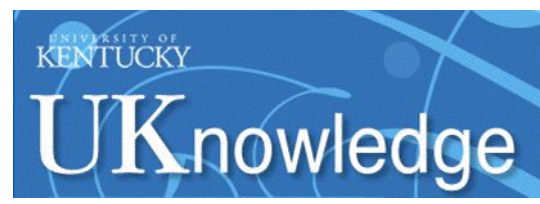

University of Kentucky

UKnowledge

$1-2016$

\title{
Values for Recreational Beach Quality in Oahu, Hawaii
}

Jerrod M. Penn

University of Kentucky, jmpenn311@gmail.com

Wuyang $\mathrm{Hu}$

University of Kentucky, wuyang.hu@uky.edu

Linda Cox

University of Hawaii at Manoa

Lara Kozloff

University of Chicago

Follow this and additional works at: https://uknowledge.uky.edu/agecon_facpub

Part of the Agricultural Economics Commons

Right click to open a feedback form in a new tab to let us know how this document benefits you.

\section{Repository Citation}

Penn, Jerrod M.; Hu, Wuyang; Cox, Linda; and Kozloff, Lara, "Values for Recreational Beach Quality in Oahu, Hawaii" (2016). Agricultural Economics Faculty Publications. 21.

https://uknowledge.uky.edu/agecon_facpub/21

This Article is brought to you for free and open access by the Agricultural Economics at UKnowledge. It has been accepted for inclusion in Agricultural Economics Faculty Publications by an authorized administrator of UKnowledge. For more information, please contact UKnowledge@lsv.uky.edu. 


\section{Values for Recreational Beach Quality in Oahu, Hawaii}

\section{Digital Object Identifier (DOI)}

https://doi.org/10.1086/683795

\section{Notes/Citation Information}

Published in Marine Resource Economics, v. 31, no. 1.

(c) 2015 MRE Foundation, Inc. All rights reserved.

The copyright holder has granted the permission for posting the article here. 


\title{
Values for Recreational Beach Quality in Oahu, Hawaii
}

\author{
Jerrod Penn, University of Kentucky; Wuyang Hu, Huazhong Agricultural University \\ and University of Kentucky; Linda Cox, University of Hawaii at Manoa; Lara Kozloff, \\ The University of Chicago Biological Sciences
}

\begin{abstract}
A B S T R A C T
Pristine coastal environments are the key to Hawaii's worldwide fame and attraction to tourists, yet their economic value remains understudied. This article examines preferences for characteristics associated with beach recreation in Oahu, Hawaii, among residents and tourists. Consideration is given to sand quality, water quality, congestion levels, and swimming safety conditions in the context of a choice experiment. The choice experiment conveys attribute levels almost entirely through pictures, and results suggest that this novel portrayal is well understood by respondents. Excessive congestion and water quality are regarded as the most important beach attributes, specifically the avoidance of poor water quality in favor of a chance to experience excellent water quality. Some evidence suggests that significantly different willingness to pay (WTP) exists among residents and tourists on Oahu with poor water quality and excellent water quality being more important to tourists, while residents place greater value on avoiding excessive congestion.
\end{abstract}

Key words: Beach recreation, choice experiment, coastal water quality, residents, tourists, willingness to pay. JEL Codes: Q25, Q26.

\section{INTRODUCTION}

As the only tropical island state in the United States, Hawaii is unique in its culture and environment. Tourists and residents alike enjoy Hawaii's world famous beaches with tourism's contribution equal to $16.4 \%$, or $\$ 10.9$ billion of Hawaii's GDP (Tian, Mak, and Leung 2011). While the economic impact of associated activities, such as snorkeling and scuba diving, has been estimated ( $\mathrm{Hu}$ et al. 2010; Bishop et al. 2011; Cesar and Van Beukering 2004), similar estimates of the economic value of beaches, a keystone of Hawaii tourism, are not widely available. Hawaii's growth and development coupled with its steep island terrain threatens its pristine coasts, especially by nonpoint source stormwater pollution, which tends to run directly

Jerrod Penn is a graduate student, Department of Agricultural Economics, University of Kentucky, 312 CE Barnhart Bldg., Lexington, KY 40546 USA (email: jerrod.penn@uky.edu). Wuyang Hu (corresponding author), Chutian Honorary Professor in the College of Economics and Management, Huazhong Agricultural University, China, and professor, Department of Agricultural Economics, University of Kentucky, 313 CE Barnhart Bldg., Lexington, KY 40546 USA (email: wuyang.hu @uky.edu). Linda Cox is a professor, Department of Natural Resources \& Environmental Management, University of Hawaii at Manoa, 1910 East-West Road, Sherman 101, Honolulu, HI 96822 USA (email: lcox@hawaii.edu). Lara Kozloff is a clinical research associate, Department of Medicine, Section of Hematology/Oncology, The University of Chicago Biological Sciences, Rm. I-207, MC2115, Chicago, IL 60637 USA (email: lara.kozloff@gmail.com).

We are grateful for feedback and comments from Christian Vossler and Leigh Maynard. Thanks are also due to Nathaniel M. Anderson, who generated the images for the valuation. This research (No. 15-04-105) was supported by the University of Kentucky Agricultural Experiment Station and is published with the approval of the Director. The research was also supported by the Huazhong Agricultural University Scientific and Technological Self-Innovation Foundation (Program \#2012RC003).

Received August 4, 2014; Accepted June 30, 2015; Published online November 2, 2015. http://dx.doi.org/10.1086/683795

Marine Resource Economics, volume 31, number 1. () 2015 MRE Foundation, Inc. All rights reserved. 0738-1360/2015/3101-0003\$10.00. 
down to recreational beaches. Consequently, stormwater pollution can significantly decrease water quality by reducing color and clarity, increasing algae blooms that endanger marine wildlife, and temporarily increasing the risk of waterborne illness such as gastroenteritis and infection (Dwight et al. 2005; Rabinovici et al. 2004; Gaffield et al. 2003). Relatively little information concerning the recreation values in Hawaii exists, although the state has a year-round beach season with continuous visits from US mainland tourists.

From 2007 to 2011, officials discouraged beach use when major rain events occurred by preemptively issuing "Brown Water Advisories," accounting for 17,878 or 98.5\% of Hawaii's water advisories and closures (Dorfman and Rosselot 2008, 2009, 2010, 2011, 2012), ultimately resulting in lost recreational opportunities for beach time by tourists and residents. To protect the economic vitality of Hawaii and the quality of life for the state's residents, the potential effects of degraded recreational quality of near-shore environments, such as poor water quality, on tourists and residents need to be understood to optimize policy prescriptions. This research focuses on the valuation of beach attributes that influence recreational beach use experiences using a choice experiment (CE) and estimates the corresponding willingness to pay (WTP). While recreational beach valuation has occurred, few have studied the globally renowned beaches of Hawaii, the primary focus of this article. Further, in this study, we compare beach valuation and changes of environmental quality for tourists versus Oahu residents.

As far as we know, little attention has explicitly focused on differences in WTP among residents and tourists for beaches, with Oh, Draper, and Dixon (2010) and Dixon, Oh, and Draper (2012) as the only to do so for three South Carolina beaches. Whereas our emphasis is on environmental quality for recreation on the beach itself, their focus was on beach development, such as the number of access points, the level of commercial development, and restrictions on beach use (e.g., pets, alcohol, fishing, etc.). Additionally, the results of both previous studies are based on the same sample of respondents, in which tourists are simply non-residents of the county where the beach is located, allowing for day-trip and nearby visitors. The distinction between a resident and a tourist in our study is much starker, since a tourist faces a much higher minimum level of effort, in terms of financial and time resources, to travel to Hawaii. Consequently, the comparison of tourists to residents is much more dichotomous relative to the previous work.

Stated preference approaches concerning water quality as a determinant of recreational choice and frequency have grown in prominence. Within the United States, almost all stated preference work has focused on the mainland, such as the Atlantic coastline (Lipton 2004; Shivlani, Letson, and Theis 2003; Oh, Draper, and Dixon 2009; Smith, Zhang, and Palmquist 1997), the Great Lakes (Murray, Sohngen, and Pendleton 2001), the Gulf of Mexico (Paudel, Caffey, and Devkota 2011), and mainland Pacific shores (Lew and Larson 2008). Additionally, a number of US beach-related papers that combined stated and revealed preference also exist (Parsons, Massey, and Tomasi 1999; Whitehead et al. 2008; Parsons et al. 2013). Empirical analysis of recreational marine water quality has also occurred globally. Considerable work has occurred in Europe (Meyerhoff, Dehnhardt, and Hartje 2010; Taylor and Longo 2010; Hynes, Tinch, and Hanley 2013; Machado and Mourato 2002), the Scandinavian peninsula (Kosenius 2010; Vesterinen et al. 2010), the Caribbean (Loomis and Santiago 2013; BeharryBorg and Scarpa 2010), and Australia (Kragt, Roebeling, and Ruijs 2009).

Few CE applications have specifically examined beach valuation. An early application by Mourato et al. (2003) estimated benefits to England and Wales of a proposed revision to the 
European Commission's Bathing Water Quality Directive. Eggert and Olsson (2009) investigated residents' values for cod stock levels, bathing water quality (described as the amount of time water quality met EU regulations), and biodiversity, concluding that mean WTP was, in absolute terms, the lowest for changes to water quality. Beharry-Borg and Scarpa (2010) considered 10 attributes to determine WTP for snorkeling and non-snorkeling Tobago tourists, including coral cover, and fish abundance. They included bathing water quality in terms of ear infections as well as water clarity as two separate attributes of water quality. Among non-snorkelers, the coefficient for an increased risk of ear infection had the highest absolute coefficient followed by reduced risk of ear infection and improved water clarity. ${ }^{1}$ More recently, Loomis and Santiago (2013) used and compared CE and CVM approaches for Puerto Rico beaches, also using pictures of four attributes with two levels for each attribute. They found that crowding and wave height were not statistically significant, and while water clarity was significant, it was second in magnitude to the appearance of trash.

Economic valuations of Hawaii and its near-shore resources have sparsely occurred. Cantrell et al. (2004) examined recreational anglers' WTP for increased catch rates of Pacific threadfin. Hu et al. (2010) valued different features of Hawaiian dolphin excursions, such as boat type and level of dolphin interaction, using CE. Given the cultural and economic significance of the island and its marine qualities, preserving Oahu's beaches is essential. Penn et al. (2014) is one of the few research studies directly related to Hawaii beaches, but their study focuses on values of alternative policies to improve beach quality. These studies show the economic importance of particular marine activities and indirectly of Hawaii's near-shore environments and beaches.

This study's CE focuses on attributes that affect the recreational value of Oahu's beaches. Understanding the relative importance of various recreational beach characteristics is crucial to maintaining or augmenting levels of benefits among users, given the scarce implementation resources available among agency leaders and managers. Further, if the values of beach characteristics differ across residents and tourists, they may affect the set of recommended strategies that maximize societal welfare.

\section{DATA AND ANALYSIS}

The CE presented here focuses on beach attributes and levels to help understand users' recreational beach choice on Oahu in order to make policy recommendations regarding benefit maximization among tourists and residents, while also identifying the potential differences between the groups. The attributes consider multiple aspects of beach recreation that are managed by various departments within Hawaii's local and state government. This was key in selecting the attributes, since the $\mathrm{CE}$ identifies the potential benefits of each attribute relative to the current level of resource use and can be used to determine if more resources should be allocated to the supervising agency in order to maximize social welfare. As such, correspondence with multiple units across Hawaii and Honolulu governments was necessary to formulate useful attribute levels, including the Department of Health's Clean Water Branch, the Department of Environmental Services' Stormwater Quality Branch, the City and County of

\footnotetext{
1. These results are reported in the random parameters model results, which was not the preferred model of the authors, but more appropriate for comparison to our results.
} 
Honolulu Ocean Safety and Lifeguard Services, non-profit environmental organizations, and previous scholarly work (Mak and Moncur 1998; Mourato et al. 2003; Oh, Dixon, and Draper 2006; Murray, Sohngen, and Pendleton 2001).

The beach valuation attributes are water quality (4 levels); sand quality (4 levels); congestion (3 levels); safety (3 levels); and the payment vehicle, round trip fuel costs (5 levels), detailed in table 1. CE often predicate water quality on one metric linked to the risk of an illness (Eggert and Olsson 2009; Mourato et al. 2003) or on water clarity (Loomis and Santiago 2013). Beharry-Borg and Scarpa (2010) included measures of water clarity and risk of illness as separate attributes of water quality. Similarly, our measure of water quality conveys risk of illness and water color/clarity within the same level of water quality so that the clearest water also has the lowest health risk, in accordance with perception results found by Smith, Croker, and McFarlane (1995). Swimming conditions were based on correspondence with Honolulu Ocean Safety and Lifeguard Services safety standards.

Typically, beach valuation studies utilize entrance, parking, or user fees (Eggert and Olsson 2009; Oh, Draper, and Dixon 2010; Beharry-Borg and Scarpa 2010), but the culture of Oahu residents dictated an alternative payment vehicle. Previous work on one particular Oahu beach by Needham et al. (2008) revealed that among 15 characteristics, clean water, absence of litter, and free access were the three most highly ranked in order of importance, at 99, 96, and $93 \%$, respectively, and user fees were significantly more important to residents than tourists. Anecdotally, rallies opposing the removal of public beach access and the implementa-

Table 1. Recreational Beach Attribute Description

\begin{tabular}{|c|c|}
\hline Attribute & Level \\
\hline Sand Quality & $\begin{array}{l}\text { Excellent: A white beach comprised entirely of sand. } \\
\text { Good: A light-tan beach comprised of } 75 \% \text { sand and } 25 \% \text { foreign materials. } \\
\text { Average: A dark-tan/light-brown beach comprised of } 50 \% \text { sand and } 50 \% \text { foreign materials. } \\
\text { Poor: A brown/gray beach comprised of } 75 \% \text { foreign materials and } 25 \% \text { sand. }\end{array}$ \\
\hline Water Quality & $\begin{array}{l}\text { Excellent: Clear, aqua-colored water; probability of illness from wading is } 5 \text { per } 1,000 \text { healthy } \\
\text { adults }(.5 \%) \text {. } \\
\text { Good: Water with visible particles floating in otherwise clear water, blue in color; probability } \\
\text { of illness from wading is } 12 \text { per } 1,000 \text { healthy adults }(1.2 \%) \text {. } \\
\text { Average: Cloudier water affecting visibility, green in color; probability of illness from wading } \\
\text { is } 19 \text { per } 1,000 \text { healthy adults ( } 1.9 \%) \text {. } \\
\text { Poor: Murky water, brownish in color; probability of illness from wading is } 25 \text { per } 1,000 \\
\text { healthy adults }(2.5 \%) \text {. }\end{array}$ \\
\hline $\begin{array}{l}\text { Swimming Safety } \\
\text { Conditions }\end{array}$ & $\begin{array}{l}\text { Very Safe: Lifeguard deems conditions safe for a majority of beachgoers; minimal wave } \\
\text { height. } \\
\text { Moderately Safe: Lifeguard deems conditions safe for experienced beachgoers; modest } \\
\text { wave height. } \\
\text { Unsafe: Lifeguard deems conditions unsafe for all beachgoers; torrential wave height. }\end{array}$ \\
\hline Congestion & $\begin{array}{l}\text { Little Congestion: The beach has ample open space and little noise. } \\
\text { Average Congestion: Congestion and noise at the beach are present but do not hinder } \\
\text { user experience. } \\
\text { Excessive Congestion: The beach is overcrowded and extremely noisy. }\end{array}$ \\
\hline $\begin{array}{l}\text { Round Trip Fuel } \\
\text { Costs }\end{array}$ & $\$ 0, \quad \$ 5, \quad \$ 10, \quad \$ 15, \quad \$ 20$ \\
\hline
\end{tabular}


tion of parking fees have occurred throughout Oahu (Cole 2008). To reduce the likelihood that the respondent would reject the hypothetical market, we used the round-trip travel cost of fuel to drive to a particular beach. The maximum fuel cost level was $\$ 20$, based on the maximum driving distance of $80 \mathrm{~km}$.

Our study is unique in the magnitude and detail of information communicated in the CE via computer-augmented pictures. As explained by Bateman et al. (2009), visual information can assist with respondent comprehension, or 'evaluability' of information, improving the accuracy of parameter estimates and corresponding WTP, and reducing inconsistencies. They compared a typical, text-based CE to a treatment that used virtual reality visualizations to depict changes in land use and found significant improvement in respondent judgment and valuation. Others have used standard photographs for limited communication on attribute levels. Beharry-Borg and Scarpa (2010) provided two photographs for nine separate attributes as a reference to communicate differences between attribute levels before the CE, but actual scenarios were still in a text format. Loomis and Santiago (2013) used photographs within each scenario of the CE on wave height, litter, congestion, and water clarity, with two levels per attribute. The first alternative always presented four photos with low quality, status-quo levels versus a second alternative with four more photos, meaning a respondent must consider eight photos to make a selection. As depicted in figure 1, except for the risk of illness and round-trip cost of fuel, our CE expresses all attributes and their levels visually within a single picture per alternative. Respondents made selections almost entirely on visual cues from one picture per alternative, except for the risk of illness and the cost of travel. In addition to the color of water depicted in the pictures, the text below the stylized pictures communicated the risk of illness as the chance for illness per every 1,000 swimmers. Prior to selecting their most preferred alternative in the actual CE, respondents were shown a pictorialized scenario as an example. The survey and CE were reviewed six times from the focus groups to the pilot test to determine the receptiveness and believability of the scenarios among residents and tourists.

Each survey contained the beach valuation $\mathrm{CE}$, questions on the respondent's recreational preferences, and socio-demographic information. Respondents were only included in the CE if they generally considered themselves recreational beach users, defined as the intention to sunbathe and swim in the ocean for at least a half an hour, and was intended to be more inclusive rather than exclusive of potential respondents. This focuses the results and WTP values as generated by beach users, to ensure that participants in the $\mathrm{CE}$ consider their responses as consequential (Carson and Groves 2007), and the potential differences from non-user values are separated for recreational beach management.

We used Sawtooth Software's randomized design to construct the CE (Sawtooth Software Inc. 2013). Randomized designs are similar to orthogonal designs, but are generally slightly less efficient than orthogonal designs when symmetric designs are involved. However, for designs that are asymmetric, such that the attributes have different numbers of levels as in our CE, randomized designs can be preferred versus purely orthogonal designs.

In randomized designs, the researcher stipulates details such as the number of choice scenarios to be shown to each respondent, number of alternatives in each choice scenario, and the choice scenario arrangement on the computer screen. The questionnaire and corresponding experimental design are then generated automatically by the computer for each respondent (Johnson 2000). In this study we use ten choice scenarios for each respondent, and each choice scenario has three alternatives. Other recent work employing this design strategy include 
Suppose that you could only choose from the beach trips below. Which would you prefer? Check the button below your choice.

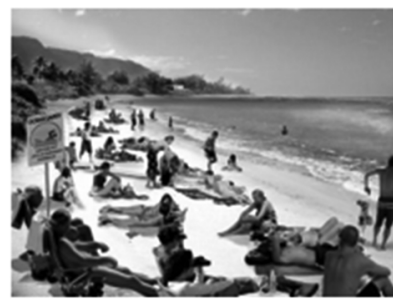

Probability of becoming ill from swimming occurs 5 out of every 1000 healthy adults.

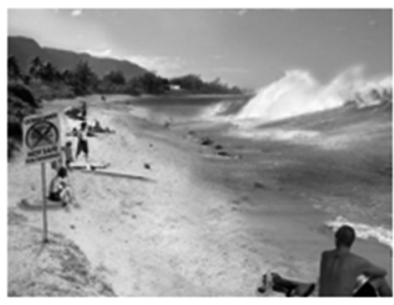

Probability of becoming ill from swimming occurs 25 out of every 1000 healthy adults.

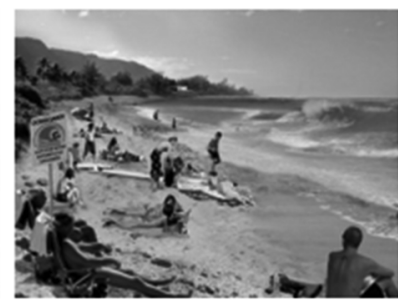

Probability of becoming ill from swimming occurs 19 out of every 1000 healthy adults.

\begin{tabular}{ccc}
\hline $\begin{array}{c}\text { Round trip travel cost of } \\
\text { gasoline is } \$ 20\end{array}$ & $\begin{array}{c}\text { Round trip travel cost of } \\
\text { gasoline is } \$ 0\end{array}$ & $\begin{array}{c}\text { Round trip travel cost of } \\
\text { gasoline is } \$ 5\end{array}$ \\
\hline
\end{tabular}

Suppose that you could only choose from the beach trips below. Which would you prefer? Check the button below your choice.

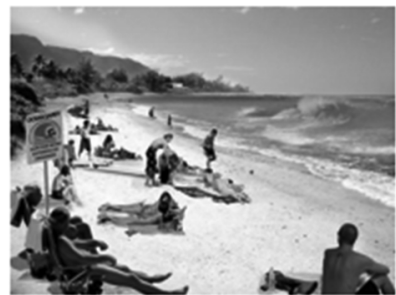

Probability of becoming ill from swimming occurs 5 out of every 1000 healthy adults.

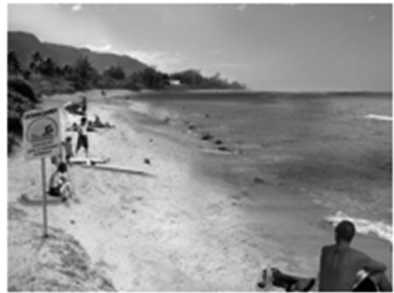

Probability of becoming ill from swimming occurs 25 out of every 1000 healthy adults.

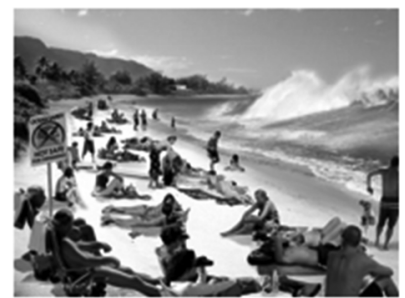

Probability of becoming ill from swimming occurs 12 out of every 1000 healthy adults.

Round trip travel cost of gasoline is $\$ 20$

\section{O}

Figure 1. Two Example Scenarios from the Beach Recreation Choice Experiment

Note: The figures above are screenshots captured for reporting purposes, but are not as detailed as what the respondent actually saw (in full color) on their computer.

Lihra, Buehlmann, and Graf (2012) (14 scenarios per respondent), Geslani et al. (2015) (10 versions, 12 scenarios per respondent), and Hoen and Koetse (2014) (30 versions, 8 scenarios per respondent). Similar to Kallas and Gil (2012), respondents were offered the three alternatives side by side and then immediately asked whether they would actually commit to their choice if they had the option not to choose at all. This follow-up question is treated as an opt- 
out alternative. The design, as well as the data generated from this design, was pretested using a convenience sample. No concerns were observed in the pilot test.

We also employed random sampling with replacement, which permits level overlap within choice scenarios. This method allows an attribute to have the same levels between two alternatives, but it does not permit two identical alternatives to appear within the same choice set. To create a more efficient design, a complete enumeration strategy was used for this study. Complete enumeration strategies consider all possible choice alternatives, except those prohibited by the research design, and choose a combination of alternatives and scenarios that produce the greatest similarity to an orthogonal design for each respondent, in terms of main effects. The alternatives presented within each choice set are also kept as different as possible so that minimal design overlap occurs (Sawtooth Software Inc. 2013).

Although the randomized design is less efficient, in general, compared to orthogonal designs of fixed scenarios, the resident and tourist surveys had D-efficiency of 99.7 and $99.8 \%$, respectively. We chose this design because first, orthogonal designs do not exist for all numbers of attributes and levels in our study. Second, the loss in efficiency that can occur with the random effects design can be offset in this study by greater flexibility and the elimination of potential attribute level position and order bias (Carlsson, Mørkbak, and Olsen 2012; Day et al. 2012). The degree of freedom needed for the roughly two dozen parameters in our models is satisfied according to the rule of thumb by Orme (2006).

Two versions of the survey instrument were developed, one for tourists and one for residents. A professional survey firm administered it from late September to mid-October 2009, requiring that each respondent be at least 18 years old and a citizen of the United States. ${ }^{2}$ To improve representation of both tourists and residents, the survey was fielded in five locations around Oahu. Survey workers approached potential respondents, inquiring about their interest in completing a 20 to 30 minute self-administered, computer-based survey. Respondents who agreed were escorted to a designated area to complete the survey via laptop. In return for completing the survey, each respondent was offered a $\$ 10$ gift card.

To model the CE data, we rely on random utility theory and use discrete choice models built upon the theory. Following Revelt and Train (1998), a mixed logit model is specified in equation 1 . The mixed logit relaxes the restrictive IIA assumption, using simulated maximum likelihood estimate to allow for variation in individual taste for various attributes. This is accomplished by introducing a probability density function for attributes that are assumed to have heterogeneous value among respondents, $h(\beta)$, enabling the estimation of the magnitude of this heterogeneity. We separated each of the attribute levels into binary-coded indicator variables. The attribute levels for beach congestion and swimming safety conditions are assumed to be normally distributed. We model two specifications for water and sand quality. The first also assumes normally distributed coefficients for all levels of water and sand quality. Using a normal distribution of the coefficient means some draws and respondents may have "opposite" signs. A proportion of the population may reasonably be assumed to prefer bigger waves or more crowds. On the other hand, the second model assumes that sand and water quality are log-normally distributed in order to impose non-negative utility for good and

\footnotetext{
2. The five-year average from 2007 to 2011 indicated that approximately $26.8 \%$ of all tourists were not from the United States. Any conclusions about the value of beach visits do not apply to tourists from abroad.
} 
excellent levels of water and sand as well as non-positive utility for poor levels of water and sand. Using the log-normal distribution has an intuitively appealing guarantee that, relative to average water and sand quality, no proportion of the population dislikes (non-negative utility) excellent/good water and sand quality or likes (non-positive utility) poor water and sand quality. Lastly, the opt-out constant and round-trip fuel costs are degenerate.

$$
\operatorname{Prob}_{i j t}=\int \frac{\exp \left(X_{i j t} \beta\right)}{\sum_{k=1}^{J} \exp \left(X_{i k t} \beta\right)} h(\beta) d(\beta) .
$$

The model was estimated using a simulated maximum likelihood estimator based on 500 Halton draws. Due to scale heterogeneity, comparing coefficient estimates across models of tourists and residents is not appropriate. Comparison between the marginal values of the attributes, which we interpret as the stated WTP to obtain an attribute level, was calculated by dividing the attribute level's coefficient estimate by the payment vehicle's coefficient estimate (the marginal utility of income), which we assumed to be constant across all respondents. This calculation removed the impact of the scale factor associated with a logit-type model. We further explore differences between tourists' and residents' WTP using the complete combinatorial test developed by Poe, Giraud, and Loomis (2005).

\section{RESULTS}

The samples are fairly representative of their respective populations and can be seen in table 2 .

In total, 411 residents participated in the survey. Due to incomplete responses and those who did not consider themselves recreational beach users, a total of 329 responses were used in the residential recreational beach $\mathrm{CE}$ analysis. Of these, 300 respondents had also completed socioeconomic information. Sample residents tended to be younger, more educated, and reported lower household incomes than the general population in Hawaii.

A total of 405 tourists participated in the survey. After eliminating those who did not complete the survey or designate themselves as recreational beach users, 351 tourists were included in the analysis, and 327 of these completed demographic information. The tourists were well-educated and earned a higher income relative to the US population. This is not

Table 2. Sample Descriptive Statistics

\begin{tabular}{lcccc}
\hline Characteristic & $\begin{array}{c}\text { Hawaii Historical } \\
\text { Average }^{1}\end{array}$ & $\begin{array}{c}\text { Hawaii Resident } \\
\text { Sample }\end{array}$ & $\begin{array}{c}\text { US Historical } \\
\text { Average }^{1}\end{array}$ & $\begin{array}{c}\text { Tourist } \\
\text { Sample }\end{array}$ \\
\hline $\begin{array}{l}\text { Median Household Income } \\
\text { Female }\end{array}$ & 464,098 & $\$ 56,930$ & $\$ 50,221$ & $\$ 75,932$ \\
Associate Degree or More, Age 25 & & $52.6 \%$ & $50.8 \%$ & $48.3 \%$ \\
$\quad$ or older & $39.1 \%$ & $59.1 \%$ & $36.3 \%$ & $68.8 \%$ \\
Age 18-25 & $11.0 \%$ & $30.7 \%$ & $11.2 \%$ & $27.8 \%$ \\
Age 55 or Older & $27.8 \%$ & $12.4 \%$ & $25.5 \%$ & $16.9 \%$ \\
Days on Oahu & & & $7.4^{2}$ & 8.0 \\
Number of Socioeconomic Responses & & 300 & & 327 \\
Choice Experiment Responses & & 329 & & 351 \\
\hline
\end{tabular}

\footnotetext{
${ }^{1}$ Based on information from the Hawaii Tourism Authority and US census.

${ }^{2}$ Based on midpoint of response categories.
} 
surprising since Hawaii's remote location makes traveling there likely more expensive than visiting other destinations closer to the tourists' homes. Compared to the average eight-day stay on Oahu in 2010, tourist respondents intended to visit Oahu for a comparable length of time, with $53 \%$ of respondents intending to stay for three to seven days and another $37 \%$ intending to stay more than one week (Hawaii Tourism Authority 2010, Table 52).

For model estimation and corresponding WTP values, Stata 13 was used, with the omitted reference attribute levels being average water quality, average sand quality, average congestion, and moderately safe swimming conditions. We included an alternative specific constant for the fourth, constructed opt-out alternative, interpreted as lost utility from not taking a trip to the beach with reference attribute levels. Model results are in table 3 and show the log-normal model results are qualitatively similar, with all of the same signs and nearly all having the same levels of significance and rank in terms of the absolute value of coefficient estimates. The model version with normally distributed attributes was slightly worse (better) for tourists (residents) compared to the specification using log-normally distributed water and sand quality attributes, so we utilize the intuitively appealing log-normal models for additional WTP analysis. Both mixed logit models were significantly better than conditional logit results (not presented; available upon request).

Every level of each attribute was significant for both tourists and residents and in the case of the normally distributed model, maintained the expected sign. At each level, a clear separation of how the attribute affected the probability of choosing a specific alternative exists, where alternatives with below-average sand quality, below-average water quality, overcrowded beaches, and unsafe swimming conditions for entering the water are less likely to be selected. Likewise, respondents were more likely to select an alternative with good or excellent water quality, good or excellent sand quality, little congestion, and safe swimming conditions. For sand and water quality, the parameter magnitude is appropriate since the likelihood of selecting an alternative is affected more by excellent water (sand) quality compared to good water (sand) quality. Roundtrip travel cost was an effective payment vehicle among tourists and residents with a statistically significant sign, as expected a priori. This implies that as the cost of the alternative increases, the respondent was less likely to visit that beach.

In the mixed logit models, the results are relatively similar with the assumption of normally distributed or log-normally distributed water and sand attribute coefficients. In absolute magnitude, poor water quality is the most important factor for tourists. Results are mixed for residents, with poor water quality and unsafe swimming conditions being the most important attribute in the normal and log-normal models, respectively. In the normal model of both samples, the standard deviation of all the random parameters is statistically significant, indicative of significant heterogeneity in preferences for attribute levels in the $\mathrm{CE}$ among tourists and residents. Similar results exist in the log-normal results with the exception of poor sand and poor water quality. More generally, water quality was an important factor in selecting a particular alternative, both as a determinant of increases and decreases in social welfare (excellent water and below-average water quality, respectively). This emphasizes that improving water quality as described in the $\mathrm{CE}$ is especially important to improve welfare of tourists and residents.

In addition to significant standard deviations indicating heterogeneous preferences of residents and tourists, they can also provide an estimated proportion of the sample that view normally distributed attributes positively, based on the associated Z-scores. A greater proportion 


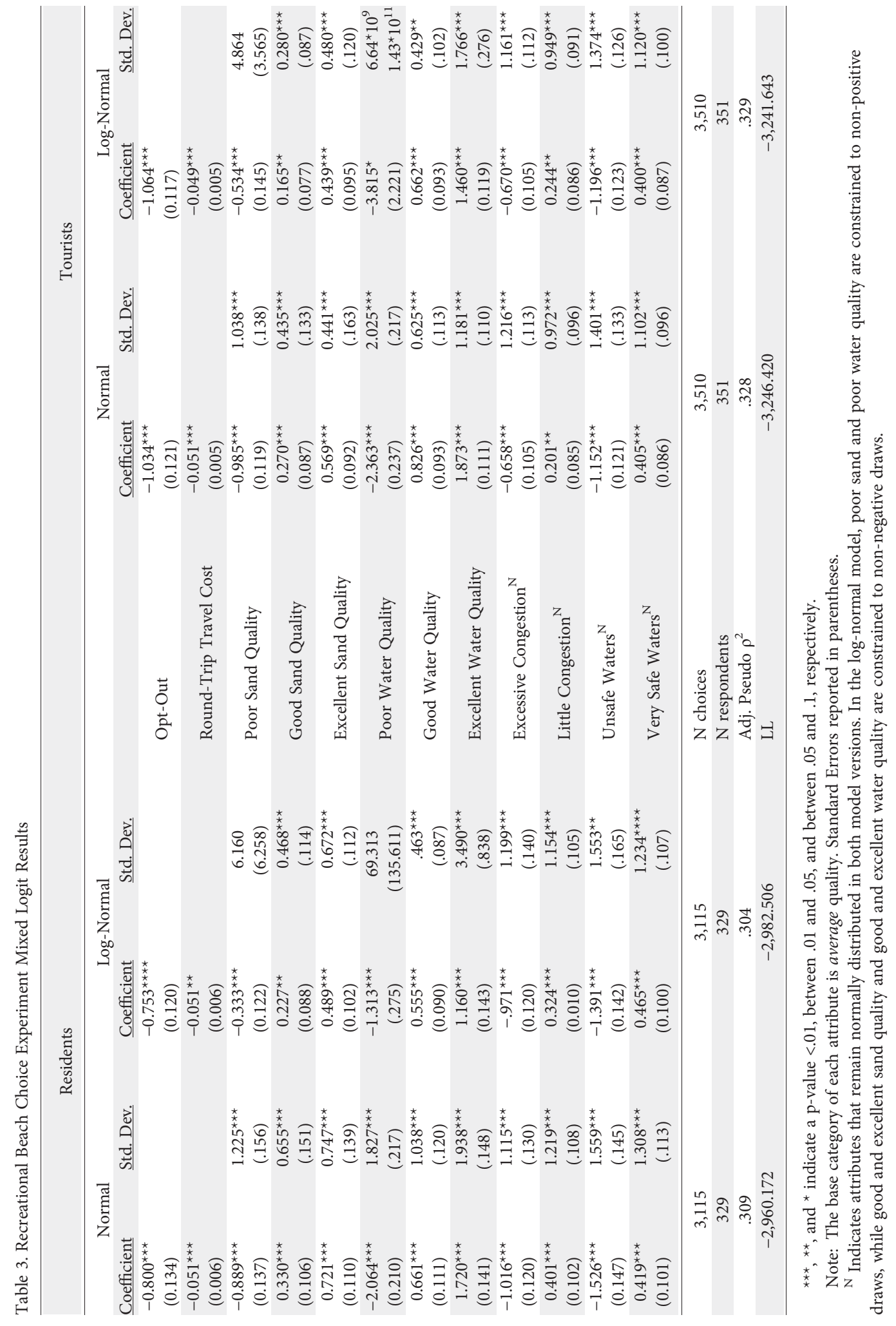


of tourists (28.42\%) is comfortable with more congested beaches, relative to residents (20.9\%), which is not surprising. For both groups, slightly less than $20 \%$ have favorable attitudes towards unsafe swimming conditions. Similarly, about $60 \%$ have positive values for less-crowded beaches, and about $64 \%$ prefer very safe swimming conditions.

Median WTP and 95 percent confidence intervals on the interval from 2.5 and $97.5 \%$ percentiles were constructed using the Krinsky-Robb approach (1986) based on 5,000 replications using the log-normal, mixed logit model results, appearing in table 4 . Thus, the calculated WTP does not directly correspond to dividing the coefficients of the attribute by the payment vehicle. The differences in WTP across the resident and tourist respondents were tested using a combinatorial test suggested by Poe, Giraud, and Loomis (2005). Accordingly, the ranking of the WTP values by magnitude matches the ranks produced from the mixed logit results.

Based on the opt-out constant, the average value lost by not going to the beach, based on the average levels for each attribute, was $\$ 14.85$ for residents and $\$ 21.72$ for tourists, which is statistically significantly greater than the value for residents. An ideal day at the beach, with excellent sand and water, little congestion, and ideal safety conditions, provides residents and tourists roughly $\$ 48.16$ and $\$ 52.08$ of value, respectively. To avoid a very poor-quality day at the beach, residents and tourists would be willing to pay $\$ 79.26$ and $\$ 127.23$, respectively. In reality, observing each characteristic simultaneously is unlikely, since, for example, crowding is likely to occur when beach and water conditions are ideal. A day at the beach can provide substantial utility for recreationists; information that may be invaluable in preserving Hawaii's near-shore environments.

Residents were willing to pay roughly $\$ 26$, while tourists were willing to pay a significantly higher amount, $\$ 78$, to avoid poor water quality. Similarly, excellent water quality was worth $\$ 23$ to residents, and significantly more, $\$ 30$, to tourists. The desire to avoid unsafe waters was valued at $\$ 24.46$ for tourists and $\$ 27.46$ for residents, with marginal significance. One reason may be that residents have more recognition of dangerous water conditions.

Table 4. Median Willingness to Pay (WTP) and 95\% Confidence Intervals for Beach Attributes

\begin{tabular}{|c|c|c|c|c|c|}
\hline \multirow[b]{2}{*}{ Attribute } & \multicolumn{2}{|c|}{ Residents } & \multicolumn{2}{|c|}{ Tourists } & \multirow[b]{2}{*}{$\begin{array}{c}\text { Equal WTP } \\
\text { p-value }\end{array}$} \\
\hline & $\begin{array}{c}\text { Median } \\
\text { WTP }^{1}\end{array}$ & $\underline{95 \% \mathrm{CI}^{2}}$ & $\begin{array}{c}\text { Median } \\
\text { WTP }^{1}\end{array}$ & $\underline{95 \% \mathrm{CI}^{2}}$ & \\
\hline Opt-Out Constant & -14.85 & $-20.06,-10.44$ & -21.72 & $-27.60,-16.96$ & .027 \\
\hline Poor Sand Quality & -6.62 & $-14.19,-3.16$ & -10.96 & $-19.36,-6.19$ & .145 \\
\hline Good Sand Quality & 4.51 & $2.08,9.71$ & 3.39 & $1.36,8.20$ & .318 \\
\hline Excellent Sand Quality & 9.65 & $6.21,15.46$ & 9.02 & $5.67,14.36$ & .414 \\
\hline Poor Water Quality & -25.99 & $-40.90,-16.62$ & -78.13 & $-244.32,-24.79$ & .041 \\
\hline Good Water Quality & 11.02 & $7.66,16.11$ & 13.57 & $9.81,18.89$ & .204 \\
\hline Excellent Water Quality & 22.94 & $17.08,31.73$ & 29.90 & $23.71,38.96$ & .095 \\
\hline Excessive Congestion & -19.19 & $-26.38,-13.87$ & -13.68 & $-19.07,-9.24$ & .078 \\
\hline Little Congestion & 6.37 & $2.49,10.90$ & 4.98 & $1.51,9.01$ & .310 \\
\hline Unsafe Waters & -27.46 & $-36.74,-20.54$ & -24.46 & $-32.31,-18.50$ & .283 \\
\hline Very Safe Waters & 9.20 & $5.21,13.95$ & 8.18 & $4.50,12.43$ & .365 \\
\hline
\end{tabular}

\footnotetext{
${ }^{1}$ Median WTP based on the $50^{\text {th }}$ percentile and ${ }^{2}$ Confidence intervals based on the 2.5 and 97.5 percentiles from the Krinsky-Robb approach of 5,000 replications using the original covariance matrix from the log-normal, mixed logit results.

3 Test of equal WTP based on complete combinatorial (1-tailed) test (Poe, Giraud, and Loomis [2005]). Log-normally distributed attributes are converted back to normal via a median transformation (i.e., $\exp \left(b_{p}\right)$ ) before conducting the test.
} 
Lastly, while congestion is relatively less important to beach choice, we find some significant differences in WTP between residents and tourists. Specifically, an overcrowded beach reduces the WTP for residents by $\$ 19.19$, which is larger than tourists' WTP of $\$ 13.68$, with marginal significance. Accordingly, the value of little congestion is greater for residents who have a WTP of $\$ 6$ relative to tourists' WTP of $\$ 5$, although these two values are not significantly different.

\section{DISCUSSION AND CONCLUSIONS}

Generally, all attributes of a recreational beach were significant factors to visitors and residents who participated in the CE. Swimming safety conditions, as reflected by wave height and the level of beach congestion, are statistically significant and persist in both the mixed and conditional logit results. This differs from the results of Loomis and Santiago (2013). We agree with their suggestion that the disparity may be due to the more apparent and pronounced differences between levels of wave height and congestion in our study, though future work and verification is essential.

For residents and tourists who participated in the survey, water quality, communicated both aesthetically and as a health risk, was significant at all levels and the most important feature of beach recreation. This result is unlike Eggert and Olsson (2009), who found water quality to have the smallest marginal WTP at 639 SEK per year (US2013 \$98.41) relative to other attributes. Water quality was measured in their study by the percentage of days with excessive foreign contaminants, a characterization of poor water quality that may be less noticeable to the general public. In the mixed logit results, the WTP to avoid poor water quality was the largest, followed by the WTP for excellent water quality. This result is consistent with Beharry-Borg and Scarpa (2010), who found that the WTP to avoid increased rates of ear infection was larger than the WTP for decreased rates of ear infection. Finally, our WTP for water quality improvement is relatively lower. For instance, the highest WTP of $\$ 40$ in our study was for an improvement from poor to average water quality, which is less than the $\$ 54$ for an improvement in water clarity estimated by Loomis and Santiago (2013), who also used pictures. Machado and Mourato (2002) found the WTP (in 1997 dollars) equals \$11 from bad to average and $\$ 8$ from average to good water quality. Households in England and Wales had a WTP of $\$ 1.57$ per year to reduce the risk of stomach illness from going to the beach by 1 in 100 , and $\$ 1.28$ to have one more day of safe water quality at the beach.

In the Oh et al. (2010) comparison of residents and tourists, they found that the WTP was significantly different in seven of eight attributes (marginally significant for the eighth attribute). The one overlapping attribute of their $\mathrm{CE}$ and ours is the level of beach congestion. In absolute terms, they found that tourists had a larger WTP to avoid moderately and highly crowded beaches. We also find a significant difference, but in the opposite direction such that Hawaii residents' WTP to avoid excessive congestion and to attain little congestion is greater than that of tourists.

We generally find that the WTP to avoid poor conditions is greater than WTP to obtain superior conditions for all attributes. These findings suggest that policymakers should strive to mitigate brown water advisories (presumably when coastal water quality is worst) to reduce the occurrence of poor water quality. Furthermore, "bad days" at the beach may have a greater impact on tourists than "good days," indicating that infrastructure and regulation may be worthwhile to keep water quality from declining further. 
Finally, using an almost exclusively pictorial design was effective, producing model results that follow economic theory and expectation. Even without communicating specific information about the actual number of people on the beach, the color of sand or water, or the risk of drowning, respondents are cognizant of the congestion, sand, water, and swimming condition levels, and respond accordingly. Pictorial approaches may even be preferable in that the number of comprehendible attributes is greater in pictures relative to blocks of text. The next step involves comparing results from a $\mathrm{CE}$ using the pictorial approach with a $\mathrm{CE}$ using a traditional text format.

Some caution may be warranted. The stark visual difference between unsafe and moderately safe swimming conditions compared to the difference of moderately and very safe swimming conditions may explain the large effect of unsafe water on beach choice. Moreover, the relative preference for poor and excellent water quality as two of the three highest coefficients in magnitude may be due to the fact that respondents focused on it more as a text and visually communicated attribute. If this occurred, then the effect of the visual water quality and the reported chance of illness are confounded. The payment vehicle was purely text and was relatively unimportant compared to the picture based-attributes. The validity of the results, given these concerns, encourages useful discussion relative to using a traditional text-based CE.

By providing results on values for characteristics of Oahu's beaches, we fill an important gap in marine environment valuation by providing results among tourists and residents for the world-famous destination of Hawaii. While evidence of heterogeneity in preferences among tourists and residents exists, our results also suggest that tourists and residents generally have the same values for environmental beach characteristics and levels for recreation. Local decisionmakers may find some relief in this result since they can concurrently support their constituents and the visitors who make a significant contribution to Hawaii's economy. In contrast, Oh et al. (2010) found significantly different WTP from different user groups for attributes related to beach development.

While investigating the value of recreational attributes of Oahu's beaches helps reveal the relative importance of these features, knowing the costs and methods to change attribute levels, as well as public attitudes towards them, such as obtrusiveness, is crucial for optimizing the allocation of resources. For instance, given the relatively lower WTP for swimming safety conditions compared to water quality, the expensive endeavor of constructing beach armor to mitigate wave transmission may be a less prudent use of resources to generate value unless beach erosion is also a central concern. Instead, installing less capital-intensive structures, such as strategically placed swales and rain gardens to divert stormwater pollution from entering Oahu's recreational waters may be more valuable, thus protecting beach water quality. Similarly, capital projects could be implemented to improve stormwater quality and increase water quality monitoring, which is crucial to measure bacteria that are associated with increased risks of illness and infection (Wade et al. 2006). Linking costs of improvements to our results can lead to cost-effective, publicly supported strategies.

\section{REFERENCES}

Bateman, I. J., B. H. Day, A. P. Jones, and S. Jude. 2009. "Reducing Gain-Loss Asymmetry: A Virtual Reality Choice Experiment Valuing Land Use Change." Journal of Environmental Economics and Management 58(1):106-18. 
Beharry-Borg, N., and R. Scarpa. 2010. "Valuing Quality Changes in Caribbean Coastal Waters for Heterogeneous Beach Visitors.” Ecological Economics 69(5):1124-39.

Bishop, R. C., D. J. Chapman, B. J. Kanninen, J. A. Krosnick, B. Leeworthy, and N. F. Meade. 2011. "Total Economic Value for Protecting and Restoring Hawaiian Coral Reef Ecosystems: Final Report." Silver Spring, MD: NOAA Office of National Marine Sanctuaries, Office of Response and Restoration, and Coral Reef Conservation Program.

Cantrell, R. N., M. Garcia, P. Leung, and D. Ziemann. 2004. “Recreational Anglers' Willingness to Pay for Increased Catch Rates of Pacific Threadfin (Polydactylus sexfilis) in Hawaii." Fisheries Research 68(1): 149-58.

Carlsson, F., M. R. Mørkbak, and S. B. Olsen. 2012. “The First Time is the Hardest: A Test of Ordering Effects in Choice Experiments." Journal of Choice Modelling 5(2):19-37.

Carson, R. T., and T. Groves. 2007. "Incentive and Informational Properties of Preference Questions." Environmental and Resource Economics 37(1):181-210.

Cesar, H. S., and P. Van Beukering. 2004. "Economic Valuation of the Coral Reefs of Hawai'i." Pacific Science 58(2):231-42.

Cole, W. 2008. "Beach Access Limits Hit Nerve." Honolulu Advertiser. http://the.honoluluadvertiser .com/article/2008/Feb/03/ln/hawaii802030356.html.

Day, B., I. J. Bateman, R. T. Carson, D. Dupont, J. J. Louviere, S. Morimoto, R. Scarpa, and P. Wang. 2012. "Ordering Effects and Choice Set Awareness in Repeat-Response Stated Preference Studies." Journal of Environmental Economics and Management 63(1):73-91.

Dixon, A. W., C. Oh, and J. Draper. 2012. "Access to the Beach: Comparing the Economic Values of Coastal Residents and Tourists.” Journal of Travel Research 51(6):742-53.

Dorfman, M., and K. S. Rosselot. 2008. Testing the Waters 2008: A Guide to Water Quality Testing at Vacation Beaches. Washington, DC: Natural Resources Defense Council.

- 2009. Testing the Waters 2009: A Guide to Water Quality Testing at Vacation Beaches. Washington, DC: Natural Resources Defense Council.

- 2010. Testing the Waters: A Guide to Water Quality at Vacation Beaches. Washington DC: National Resources Defense Council.

. 2011. Testing the Waters: A Guide to Water Quality at Vacation Beaches. Washington DC: National Resources Defense Council.

- 2012. Testing the Waters: A Guide to Water Quality at Vacation Beaches. Washington DC: National Resources Defense Council.

Dwight, R., L. Fernandez, D. Baker, J. Semenza, and B. Olson. 2005. "Estimating the Economic Burden from Illnesses Associated with Recreational Coastal Water Pollution-A Case Study in Orange County, California." Journal of Environmental Management 76(2):95-103.

Eggert, H., and B. Olsson. 2009. "Valuing Multi-Attribute Marine Water Quality." Marine Policy 33 (2):201-6.

Gaffield, S. J., R. L. Goo, L. A. Richards, and R. J. Jackson. 2003. "Public Health Effects of Inadequately Managed Stormwater Runoff." American Journal of Public Health 93(9):1527-33.

Geslani, C., M. K. Loke, M. Barnes-Mauthe, and P. Leung. 2015. "Seafood Purchasing Preferences of Hawaii Chefs: Comparing Actual Purchase to Stated Preferences From Conjoint Choice Experiment." Journal of International Food \& Agribusiness Marketing 27(1):50-63.

Hawaii Tourism Authority. 2010. “2010 Annual Visitor Resarch Report.” http://www.hawaiitourism authority.org/default/assets/File/reports/visitor-statistics/2010\%20Annual\%20Visitors\%20Research\%20 Report\%20(Webposting\%208-12-11)(1).pdf.

Hoen, A., and M. J. Koetse. 2014. "A Choice Experiment on Alternative Fuel Vehicle Preferences of Private Car Owners in the Netherlands." Transportation Research Part A: Policy and Practice 61: 199-215. 
Hu, W., K. Boehle, L. J. Cox, and M. Pan. 2010. "Economic Values of Dolphin Excursions In Hawaii: A Stated Choice Analysis." Marine Resource Economics 24(1):61-76.

Hynes, S., D. Tinch, and N. Hanley. 2013. "Valuing Improvements to Coastal Waters using Choice Experiments: An Application to Revisions of the EU Bathing Waters Directive.” Marine Policy 40:137-44.

Johnson, R. M. 2000. “Understanding HB: An Intuitive Approach.” Sawtooth Software Inc., Sequim, WA.

Kallas, Z., and J. M. Gil. 2012. "A Dual Response Choice Experiments (DRCE) Design to Assess Rabbit Meat Preference in Catalonia: A Heteroscedastic Extreme-Value Model.” British Food Journal 114 (10):1394-413.

Kosenius, A.-K. 2010. "Heterogeneous Preferences for Water Quality Attributes: The Case of Eutrophication in the Gulf of Finland, the Baltic Sea." Ecological Economics 69(3):528-38.

Kragt, M. E., P. C. Roebeling, and A. Ruijs. 2009. "Effects of Great Barrier Reef Degradation on Recreational Reef-Trip Demand: A Contingent Behaviour Approach.” Australian Journal of Agricultural and Resource Economics 53(2):213-29.

Krinsky, I., and A. L. Robb. 1986. "On Approximating the Statistical Properties of Elasticities." The Review of Economics and Statistics 68(4):715-9.

Lew, D. K., and D. M. Larson. 2008. "Valuing a Beach Day with a Repeated Nested Logit Model of Participation, Site Choice, and Stochastic Time Value.” Marine Resource Economics 23(3):233-52.

Lihra, T., U. Buehlmann, and R. Graf. 2012. "Customer Preferences for Customized Household Furniture." Journal of Forest Economics 18(2):94-112.

Lipton, D. 2004. “The Value of Improved Water Quality to Chesapeake Bay Boaters.” Marine Resource Economics 19(2):265-70.

Loomis, J., and L. Santiago. 2013. "Economic Valuation of Beach Quality Improvements: Comparing Incremental Attribute Values Estimated from Two Stated Preference Valuation Methods.” Coastal Management 41(1):75-86.

Machado, F. S., and S. Mourato. 2002. "Evaluating the Multiple Benefits of Marine Water Quality Improvements: How Important are Health Risk Reductions?" Journal of Environmental Management 65(3):239-50.

Mak, J., and J. Moncur. 1998. "Political Economy of Protecting Unique Recreational Resources: Hanauma Bay, Hawaii." Ambio 27(3):217-23.

Meyerhoff, J., A. Dehnhardt, and V. Hartje. 2010. “Take Your Swimsuit Along: The Value of Improving Urban Bathing Sites in the Metropolitan Area of Berlin.” Journal of Environmental Planning and Management 53(1):107-24.

Mourato, S., S. Georgiou, E. Ozdemiroglu, J. Newcombe, and A. Howarth. 2003. Bathing Water Directive Revisions: What are the Benefits to England and Wales? A Stated Preference Study. CSERGE Working Paper ECM 03-12. Center for Social and Economic Research on the Global Environment, East Anglia, Norwich.

Murray, C., B. Sohngen, and L. Pendleton. 2001. "Valuing Water Quality Advisories and Beach Amenities in the Great Lakes." Water Resources Research 37(10):2583-90.

Needham, M. D., R. L. Collins, W. M. Connor, and M. J. W. Culnane. 2008. Recreation Carrying Capacity and Management at Kailua Beach Park on Oahu, Hawaii. Final project report for Hawaii Coral Reef Initiative - Research Program. Corvallis: Oregon State University, Department of Forest Ecosystems and Society.

Oh, C., A. Dixon, and J. Draper. 2006. "Visitor Needs Assessment and Economic Analysis of South Carolina Beaches.” Department of Parks, Recreation and Tourism Management, Clemson, SC.

Oh, C., J. Draper, and A. W. Dixon. 2009. “Assessing Tourists' Multi-Attribute Preferences for Public Beach Access.” Coastal Management 37(2):119-35.

_. 2010. "Comparing Resident and Tourist Preferences for Public Beach Access and Related Amenities.” Ocean \& Coastal Management 53(5):245-51. 
Orme, B. K. 2006. Getting Started with Conjoint Analysis: Strategies for Product Design and Pricing Research. Madison, WI: Research Publishers LLC.

Parsons, G. R., Z. Chen, M. K. Hidrue, N. Standing, and J. Lilley. 2013. "Valuing Beach Width for Recreational Use: Combining Revealed and Stated Preference Data." Marine Resource Economics 28 (3):221-41.

Parsons, G. R., D. M. Massey, and T. Tomasi. 1999. "Familiar and Favorite Sites in a Random Utility Model of Beach Recreation.” Marine Resource Economics 14(4):299-315.

Paudel, K. P., R. H. Caffey, and N. Devkota. 2011. "An Evaluation of Factors Affecting the Choice of Coastal Recreational Activities." Journal of Agricultural and Applied Economics 43(2):167-79.

Penn, J., W. Hu, L. Cox, and L. Kozloff. 2014. "Resident and Tourist Preferences for Stormwater Management Strategies in Oahu, Hawaii." Ocean \& Coastal Management 98:79-85.

Poe, G. L., K. L. Giraud, and J. B. Loomis. 2005. "Computational Methods for Measuring the Difference of Empirical Distributions.” American Journal of Agricultural Economics 87(2):353-65.

Rabinovici, S., R. L. Bernknopf, A. M. Wein, D. L. Coursey, and R. L. Whitman. 2004. "Economic and Health Risk Trade-Offs of Swim Closures at a Lake Michigan Beach.” Environmental Science \& Technology 38(10):2737-45.

Revelt, D., and K. E. Train. 1998. "Mixed Logit with Repeated Choices: Households' Choices of Appliance Efficiency Level." Review of Economics and Statistics 80(4):647-57.

Sawtooth Software Inc. 2013. The CBC System for Choice-Based Conjoint Analysis Version 8. Orem, UT.

Shivlani, M. P., D. Letson, and M. Theis. 2003. "Visitor Preferences for Public Beach Amenities and Beach Restoration in South Florida." Coastal Management 31(4):367-85.

Smith, D. G., G. F. Croker, and K. McFarlane. 1995. "Human Perception of Water Appearance: 1. Clarity and Colour for Bathing and Aesthetics." New Zealand Journal of Marine and Freshwater Research 29(1):29-43.

Smith, V. K., X. Zhang, and R. B. Palmquist. 1997. "Marine Debris, Beach Quality, and Non-Market Values." Environmental and Resource Economics 10(3):223-47.

Taylor, T., and A. Longo. 2010. "Valuing Algal Bloom in the Black Sea Coast of Bulgaria: A Choice Experiment Approach.” Journal of Environmental Management 91(10):1963-71.

Tian, E., J. Mak, and P. Leung. 2011. "The Direct and Indirect Contributions of Tourism to Regional GDP: Hawaii.” Economic Research Organization, University of Hawaii at Manoa, Honolulu, HI.

Vesterinen, J., E. Pouta, A. Huhtala, and M. Neuvonen. 2010. "Impacts of Changes in Water Quality on Recreation Behavior and Benefits in Finland.” Journal of Environmental Management 91(4):984-94.

Wade, T. J., R. L. Calderon, E. Sams, M. Beach, K. P. Brenner, A. H. Williams, and A. P. Dufour. 2006. "Rapidly Measured Indicators of Recreational Water Quality are Predictive of Swimming-Associated Gastrointestinal Illness.” Environmental Health Perspectives 14(1):24-8.

Whitehead, J. C., C. F. Dumas, J. Hill, and B. Buerger. 2008. "Valuing Beach Access and Width with Revealed and Stated Preference Data.” Marine Resource Economics 23(2):119-35. 